\title{
Renal resistive index and its association with insulin resistance in patients with Type 2 Diabetes mellitus
}

\author{
*Santha.K ${ }^{1}$, Balu Mahendran.K ${ }^{1}$, Perumal $. K . K^{2}$, Inmozhi.R ${ }^{1}$, Sethupathy. $S^{1}$ \\ ${ }^{I}$ Division of Biochemistry, Rajah Muthiah Medical College and Hospital, Annamalai University, \\ Annamalainagar, Tamil Nadu, India. \\ ${ }^{2}$ Division of Medicine, Rajah Muthiah Medical College and Hospital, Annamalai University, Annamalainagar, \\ Tamil Nadu, India.
}

\begin{abstract}
Background: Diabetic nephropathy (DN) is the leading cause of end-stage renal disease (ESRD) and a major cause of cardiovascular mortality.

Aim: The aim of this study is to assess the significance between renal resistive index with albumin creatinine ratio and to explore possible correlation with HbAlc, homeostasis model assessment-estimated insulin resistance (HOMA-IR) in type 2 diabetic patients.

Materials and methods: Sixty type 2 diabetic patients with more than 5 year diabetic duration in the age group of 35 to 60 years were selected for this study and 30 age matched healthy individuals were selected as control group. The renal Doppler studies were performed using a low-frequency ultrasound transducer and a standardized diagnostic scanning protocol for image acquisition. Glycated hemoglobin (HbAlC), Insulin, microalbumin were analyzed by conventional standardized methods.

Results: Interlobar and Arcuate artery Renal resistive index values were significantly increased in diabetic patients compared with controls and also significantly increased values were observed in microalbuminuric diabetics compared with normoalbuminuric diabetics. The Interlobar artery resistive index levels were positively correlated with the albumin creatinine ratio (ACR), glycated hemoglobin (HbAlC) and insulin resistance.
\end{abstract}

Conclusion: RRI might be a non invasive diagnostic marker of early renal vascular changes and is positively correlated with insulin resistance and HbAlc in type 2 diabetes mellitus.

Keywords: Diabetic nephropathy, Renal resistive index, Insulin resistance, Glycated hemoglobin (HbAlC)

\section{Introduction}

Diabetes mellitus is associated with microvascular and macrovascular complications. Diabetic nephropathy (DN) is a primary cause of end-stage renal disease (ESRD) and cardiovascular mortality [1,2]. Due to the global increase in prevalence of diabetes, there has been a concomitant rise in the number of patients with diabetic nephropathy indicating a prevalence of $30-40 \%$ of patients with type 1 (T1DM) and type 2 diabetes (T2DM) being affected [3,4]. Microalbuminuria is the gold standard for detection and prediction of diabetic nephropathy in clinical practice. At the same time, microalbuminuria represents a marker of the generalized endothelial dysfunction present in DM, linking renal involvement with cardiovascular and cerebral impairment [5, 6]. However, many patients, who were normoalbuminuric and just recently had positive test for microalbuminuria, have advanced renal histopathological changes, decreased glomerular filtration rate (GFR) and progressive loss of kidney function [7, 8].

Ultrasound and Doppler imaging has also traditionally been used in the assessment of chronic renal disease. Not only does Doppler ultrasonography detect renal macroscopic vascular abnormalities but it also identifies changes in blood flow at the microvascular level [9]. Renal resistive index (RI), as a promising marker for various types of vascular damage used in detecting reno-vascular diseases, showing to be a non-invasive, safe, low cost and repeatable tool [10,11]. Renal RI (RRI) is defined as a ratio of the difference between maximum and minimum (end-diastolic) flow velocity to maximum flow velocity derived from the Doppler spectrum of intrarenal (segmental/interlobar) arteries [12]. RRI provides prognostic information relating to systemic vasculature and an elevated RRI is associated with adverse outcomes in hypertensive, diabetic, and elderly patients [13-16]. So, in the present study we aimed to evaluate the relation between renal resistive index with albumin creatinine ratio and to find the possible correlation with $\mathrm{HbAlc}$, homeostasis model assessmentestimated insulin resistance (HOMA-IR) in type 2 diabetic patients.

\section{Materials and methods}

The study groups comprised of 60 type 2 diabetic patients of both sexes, aged between 35-60 years on oral hypoglycemic drugs, attending diabetic out-patient department of Rajah Muthiah Medical College and 
Hospital, Annamalai University, Annamalainagar, Tamil Nadu, India, were selected for our study. We excluded the patients based on the following criteria: patients on insulin, hypertension, smokers, alcoholics, tobacco chewers, abnormal urinary sediment, urinary tract infection, history of other renal disease and active or chronic persistent infection or inflammatory disorders, neoplastic disorders, uncontrolled thyroid disorders, severe liver dysfunction, history of acute myocardial infarction, stroke, and occlusive peripheral vascular disease. The included diabetic patients were categorized into two groups based on urinary albumin creatinine ratio (ACR) as patients (30 no) with normoalbuminuria (<30 mg/g creatinine), patients (30 no) with microalbuminuria (30-299 $\mathrm{mg} / \mathrm{g}$ creatinine). Thirty healthy age, sex matched subjects were selected as controls. The informed consent was obtained from all the study subjects and the study was approved by the Institutional Human Ethics Committee (IHEC). Experiments were done in accordance with Helsinki declaration of 1975.

\section{Biochemical analysis:}

A random spot urine and fasting blood samples were obtained from the subjects immediately after enrolment. Blood samples were centrifuged at $2000 \times \mathrm{g}$ for $10 \mathrm{~min}$. Samples were analyzed for fasting blood glucose, lipid Profile(Total Cholesterol, HDL, Triglycerides), by using Auto analyzer. HbA1C estimated by Ion exchange resin method and Insulin assessed by ELISA and the 2 hour post prandial venous blood sample collected for plasma glucose (PPG) analysis. Homeostasis model assessment for insulin resistance evaluation (HOMA-IR) was calculated using the equation: fasting plasma insulin $\times$ glucose/22.5 [17]. Urine samples were analyzed for microalbumin, creatinine by using auto analyzer.

\section{Measurement of ultrasound Doppler Renal resistive index (RRI):}

Ultra sound Doppler renal examination was performed with a $3.5 \mathrm{MHz}$ convex transducer (Toshiba Medical Systems, Tochigi, Japan). Initially routine renal B-mode US examinations were performed for each patient. Ultrasound testing was performed on the same day and measurements was preferentially be repeated in different parts of both kidneys (superior, median, and lower) out of which at least three reproducible waveforms have been obtained. RRI is calculated with the following formula: (peak systolic velocity - end diastolic velocity)/ peak systolic velocity, and the mean value of three measurements at each kidney. In each subject, RI at the interlobular and arcuate artery near the border of the central echo complex was measured [18].

\section{Statistical analysis}

Statistical analyses were carried out with SPSS 20.0. Values were expressed as mean \pm standard deviation, $\mathrm{p}$ value $<0.05$ was considered statistically significant. Normally distributed data were analyzed by using one-way ANOVA. The Pearson correlation test was used for correlation analysis.

\section{Results}

Table 1: Baseline data of controls, normoalbuminuric and microalbuminuric type 2 diabetic patients

\begin{tabular}{|l|c|c|c|}
\hline \multicolumn{1}{|c|}{ Parameters } & Controls $(\mathbf{n = 3 0})$ & $\begin{array}{c}\text { Normoalbuminuric } \\
\text { T2DM }(\mathbf{n = 3 0})\end{array}$ & $\begin{array}{c}\text { Microalbuminuric } \\
\text { T2DM }(\mathbf{n = 3 0})\end{array}$ \\
\hline Age & $47.7 \pm 3.9$ & $48.1 \pm 6.7$ & $49.1 \pm 4.4$ \\
\hline Body mass index (BMI) & $24.3 \pm 1.3$ & $26.9 \pm 3.6^{\mathrm{a}^{*}}$ & $26.5 \pm 3.5^{\text {a\# }}$ \\
\hline Waist/Hip ratio & $0.91 \pm 0.03$ & $0.92 \pm 0.06$ & $0.92 \pm 0.04$ \\
\hline Systolic BP(mmH) & $113.9 \pm 7.1$ & $123.5 \pm 15.5^{\text {a\#t }}$ & $126.6 \pm 12.5^{\text {a }^{*}}$ \\
\hline Diastolic BP $(\mathrm{mm} \mathrm{Hg})$ & $74.1 \pm 3.4$ & $78.7 \pm 7.5^{\text {a\# }}$ & $78.5 \pm 6.6^{\text {at }}$ \\
\hline
\end{tabular}

a - Controls vs Normoalbuminuria T 2DM, Microalbuminuria T2DM

b -Normoalbuminuria T 2DM vs Microalbuminuria T 2 DM

* $\mathrm{p}$ value $<0.001$, \# $\mathrm{p}$ value $<0.05$

Data are expressed as mean $\pm \mathrm{SD}, \mathrm{p}<0.05$ was considered statistically significant.

Table 2: Clinical data of controls, normoalbuminuric and microalbuminuric type 2 diabetic patients

\begin{tabular}{|c|c|c|c|}
\hline Parameters & Controls $(\mathbf{n}=\mathbf{3 0})$ & $\begin{array}{l}\text { Normoalbuminur } \\
\text { ic } \quad \text { T2DM }(\mathbf{n}=30)\end{array}$ & $\begin{array}{c}\text { Microalbumi } \\
\text { nuric } \\
\text { T2DM }(\mathbf{n}=\mathbf{3 0})\end{array}$ \\
\hline $\begin{array}{c}\text { Urine albumin Creatinine ratio } \\
\text { (mg/gm. of creatinine) }\end{array}$ & $18.6 \pm 2.7$ & $22.8 \pm 3.2^{\mathrm{a}^{*}}$ & $127.3 \pm 40.9$ \\
\hline $\mathrm{FPG}(\mathrm{mg} / \mathrm{dl})$ & $82.2 \pm 5.7$ & $123.0 \pm 22.6^{\mathrm{a}^{*}}$ & $135.3 \pm 33.4^{\mathrm{a}^{*}}$ \\
\hline PPG(mg/dl) & $107.8 \pm 9.2$ & $170 \pm 20.7^{\mathrm{a}^{*}}$ & $\underset{\mathrm{a}^{*}, \mathrm{~b}^{*}}{203.4 \pm 42.4}$ \\
\hline HbA1C & $5.5 \pm 0.4$ & $7.1 \pm 0.8^{\mathrm{a}^{*}}$ & $8.2 \pm 0.9^{\mathrm{a}^{*}, \mathrm{~b}^{*}}$ \\
\hline Serum urea(mg/dl) & $24.5 \pm 4.3$ & $27.8 \pm 4.2^{\text {att }}$ & $31.4 \pm 5.0^{\mathrm{a}^{*}, 6+b}$ \\
\hline Serum creatinine $(\mathrm{mg} / \mathrm{dl})$ & $0.6 \pm 0.1$ & $0.7 \pm 0.2$ & $0.9 \pm 0.3^{\mathrm{a}^{*}, \mathrm{~b} \#}$ \\
\hline
\end{tabular}




\begin{tabular}{|c|c|c|c|}
\hline Serum cholesterol $(\mathrm{mg} / \mathrm{dl})$ & $168.9 \pm 8.8$ & $185.3 \pm 19.4^{\mathrm{a}^{*}}$ & $194.9 \pm 22.7^{\mathrm{a}^{\mathrm{a}^{*}}}$ \\
\hline Serum Triglycerides $(\mathrm{mg} / \mathrm{dl})$ & $95.9 \pm 7.1$ & $130.1 \pm 35.9^{\mathrm{a}^{*}}$ & $140.2 \pm 35.0^{\mathrm{a}^{*}}$ \\
\hline HDL cholesterol $(\mathrm{mg} / \mathrm{dl})$ & $44.0 \pm 2.4$ & $39.2 \pm 2.9^{\mathrm{a}^{*}}$ & $38.5 \pm 2.4^{\mathrm{a}^{*}}$ \\
\hline LDL cholesterol $(\mathrm{mg} / \mathrm{dl})$ & $105.7 \pm 8.8$ & $120.0 \pm 16.0^{\mathrm{a}^{*}}$ & $128.3 \pm 22.2^{\mathrm{a}^{*}}$ \\
\hline Insulin $(\mu \mathrm{IU} / \mathrm{mL})$ & $6.4 \pm 0.7$ & $10.3 \pm 2.7^{\mathrm{a}^{*}}$ & $14.2 \pm 3.4^{\mathrm{a}^{*}, \mathrm{~b}^{*}}$ \\
\hline HOMA-IR & $1.3 \pm 0.18$ & $3.1 \pm 0.9^{\mathrm{a}^{*}}$ & $4.7 \pm 1.6^{\mathrm{a}^{*}, \mathrm{~b}^{*}}$ \\
\hline
\end{tabular}

a - Controls vs Normoalbuminuria T 2DM, Microalbuminuria T2DM

b -Normoalbuminuria T 2DM vs Microalbuminuria T $2 \mathrm{DM}$

* $\mathrm{p}$ value $<0.001$, \# $\mathrm{p}$ value $<0.05$

Data are expressed as mean $\pm \mathrm{SD}, \mathrm{p}<0.05$ was considered statistically significant

Table 3: Interlobar (IL), arcuate artery (ARC) resistive index in controls, normoalbuminuric and microalbuminuric type 2 diabetic patients

\begin{tabular}{|c|c|c|c|}
\hline Parameters & $\begin{array}{c}\text { Controls } \\
(\mathrm{n}=30)\end{array}$ & $\begin{array}{c}\text { Normoalbuminuria } \\
\text { T2DM }(\mathrm{n}=30)\end{array}$ & $\begin{array}{c}\text { Microalbuminuria } \\
\text { T2DM }(\mathrm{n}=30)\end{array}$ \\
\hline Right Kidney IL RI & $0.54 \pm 0.02$ & $0.66 \pm 0.05^{\mathrm{a}^{*}}$ & $0.83 \pm 0.1^{\mathrm{a}^{*}, \mathrm{~b}^{*}}$ \\
\hline Left Kidney IL RI & $0.53 \pm 0.05$ & $0.68 \pm 0.06^{\mathrm{a}^{*}}$ & $0.79 \pm 0.1^{\mathrm{a}^{*}, \mathrm{~b}^{*}}$ \\
\hline Right Kidney ARC RI & $0.51 \pm 0.06$ & $0.72 \pm 0.07^{\mathrm{a}^{*}}$ & $0.83 \pm 0.1^{\mathrm{a}^{*}, \mathrm{~b}^{*}}$ \\
\hline Left Kidney ARC RI & $0.55 \pm 0.03$ & $0.64 \pm 0.04^{\mathrm{a}^{*}}$ & $0.82 \pm 0.1^{\mathrm{a}^{*}, \mathrm{~b}^{*}}$ \\
\hline
\end{tabular}

a - Controls vs Normoalbuminuria T 2DM, Microalbuminuria T2DM

b -Normoalbuminuria T 2DM vs Microalbuminuria T 2 DM

* $\mathrm{p}$ value $<0.001$, \# $\mathrm{p}$ value $<0.05$

Data are expressed as mean $\pm \mathrm{SD}, \mathrm{p}<0.05$ was considered statistically significant

Table 4: Correlation between ACR\& measured parameters in type 2 diabetic patients

\begin{tabular}{|c|c|}
\hline Parameters & Correlation Coefficient(r) \\
\hline Right Kidney IL RI & $0.658^{* *}$ \\
\hline Left Kidney IL RI & $0.763^{* *}$ \\
\hline Right Kidney ARC RI & $0.282^{*}$ \\
\hline Left Kidney ARC RI & $0.367^{* *}$ \\
\hline
\end{tabular}

*Correlation is significant at the 0.05 level (2-tailed).

**Correlation is significant at the 0.01 level (2-tailed).

Table 5: Correlation between HOMA IR \&measured parameters in type 2 diabetic patients

\begin{tabular}{|c|c|}
\hline Parameters & Correlation Coefficient(r) \\
\hline Right Kidney IL RI & $0.569^{* *}$ \\
\hline Left Kidney IL RI & $0.442^{* *}$ \\
\hline Right Kidney ARC RI & $0.295^{* *}$ \\
\hline Left Kidney ARC RI & 0.232 \\
\hline
\end{tabular}

*Correlation is significant at the 0.05 level (2-tailed).

**Correlation is significant at the 0.01 level (2-tailed).

Table 6: Correlation between HbA1c\&measured parameters in type 2 diabetic patients

\begin{tabular}{|c|c|}
\hline Parameters & Correlation Coefficient(r) \\
\hline Right Kidney IL RI & $0.485^{* *}$ \\
\hline Left Kidney IL RI & $0.383^{* *}$ \\
\hline Right Kidney ARC RI & 0.213 \\
\hline Left Kidney ARC RI & $0.312^{*}$ \\
\hline
\end{tabular}

*Correlation is significant at the 0.05 level (2-tailed).

**Correlation is significant at the 0.01 level (2-tailed). 


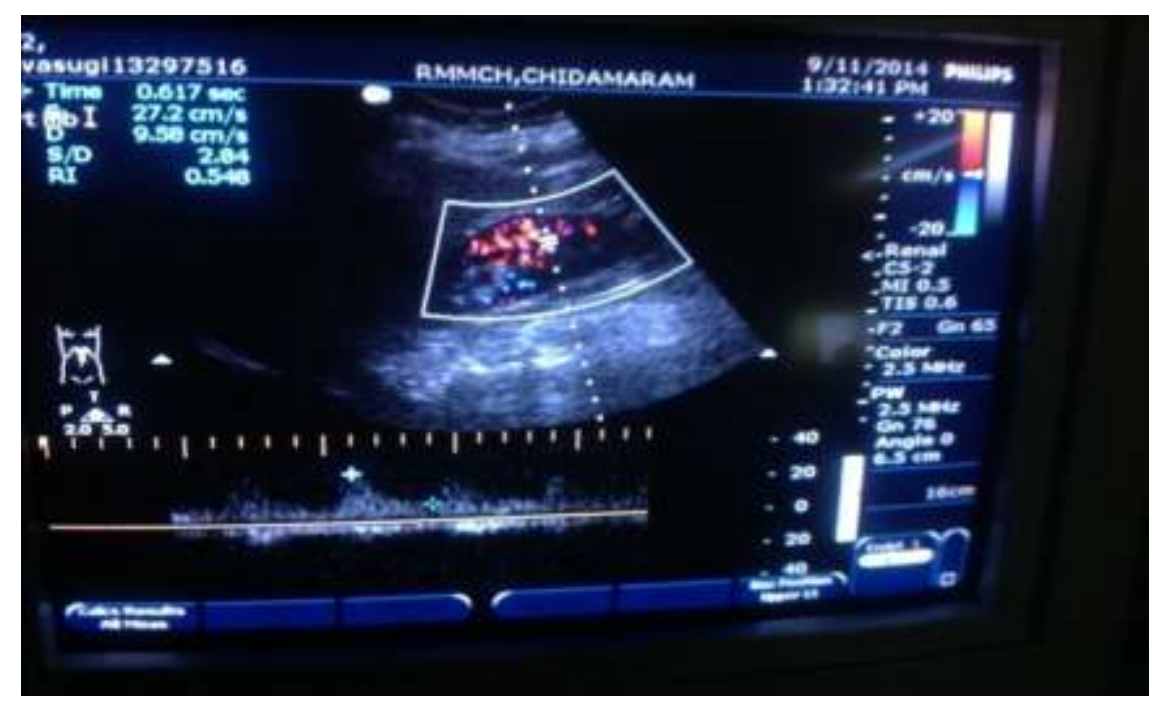

Figure 1: Interlobar artery resistive index in control subject

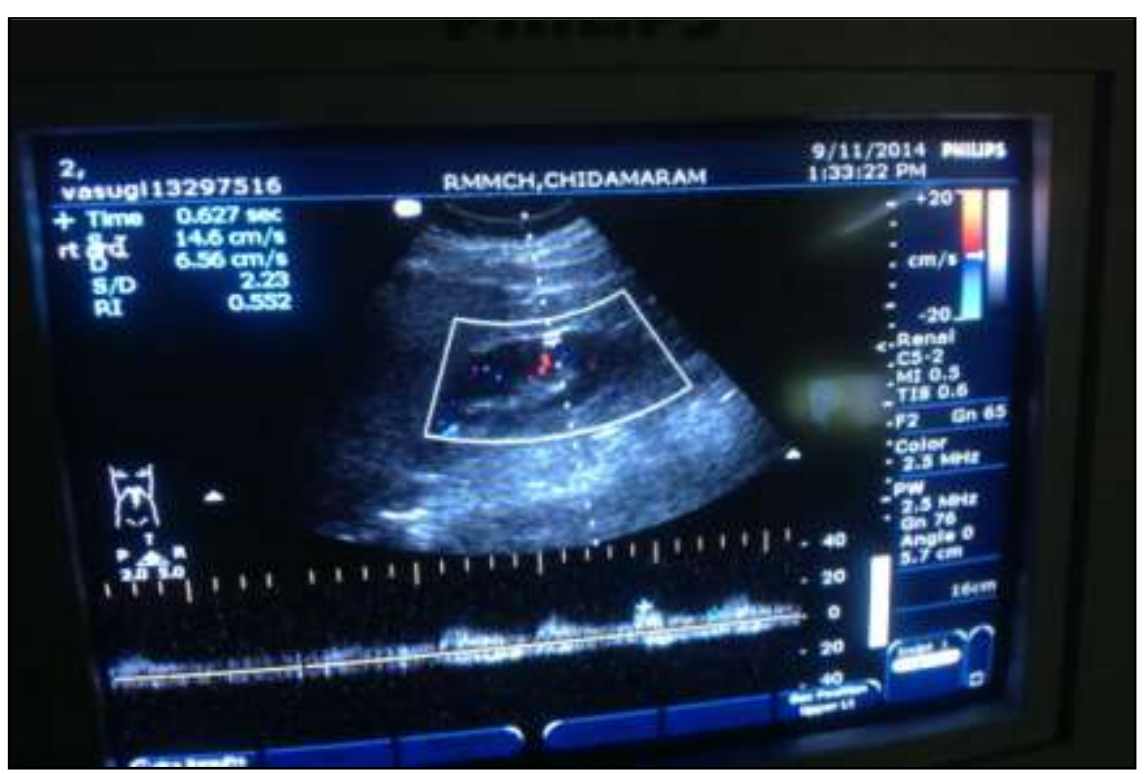

Figure 2: Arcuate artery resistive index in control subject

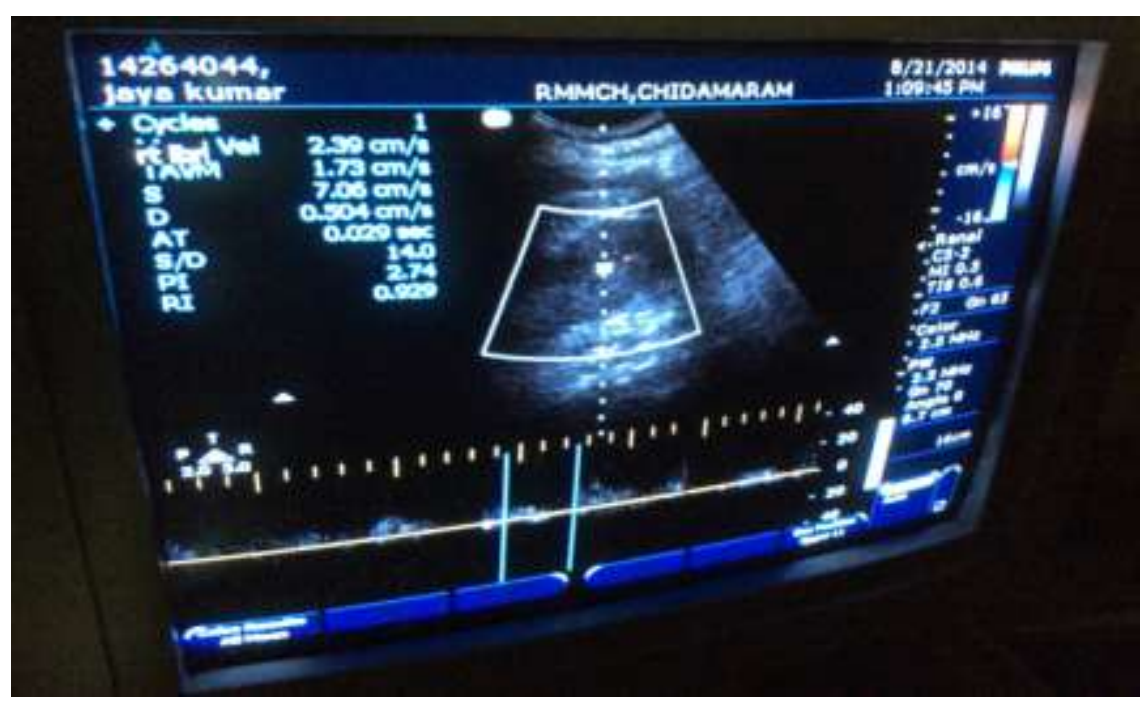

Figure 3: Interlobar artery resistive index in diabetic subject 


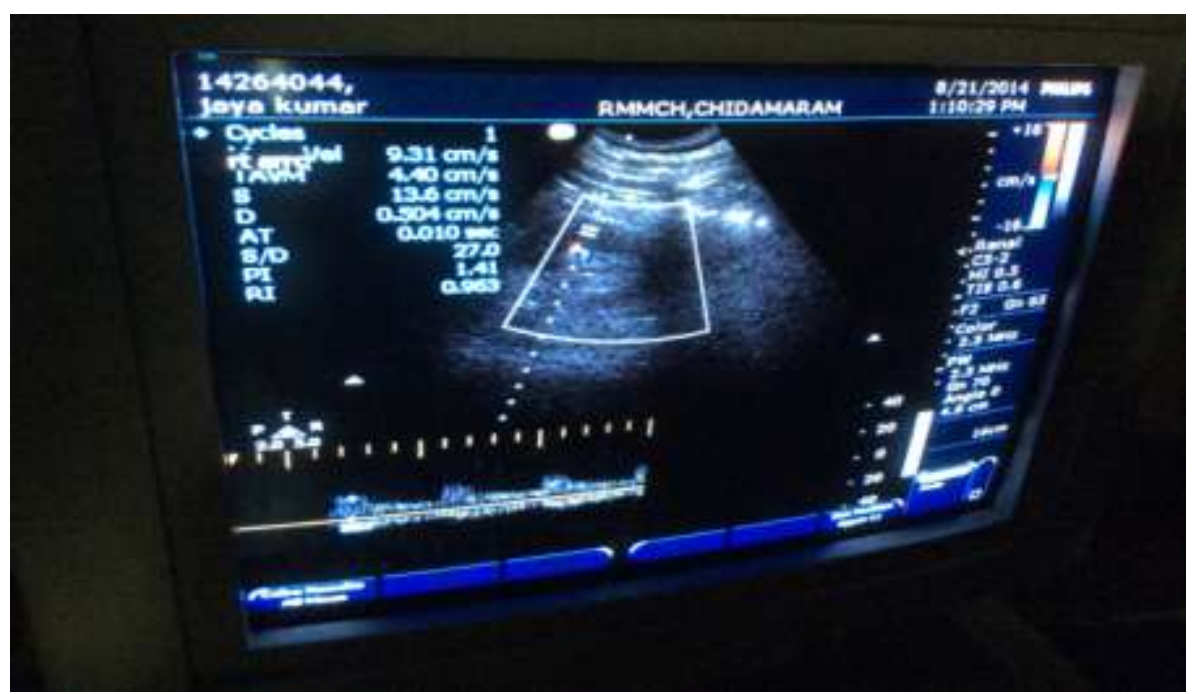

Figure 4: Arcuate artery resistive index in diabetic subject

\section{Discussion}

Diabetic nephropathy is the most common cause of end-stage renal disease in the world, and could account for high mortality rate in patients with diabetes [18]. Chronic hyperglycemia induces dysfunction in various cell types of the kidney, ultimately leading to progressive renal failure [19-25]. The annual incidence of this disease has more than doubled in the past decade, and at present it accounts for almost $50 \%$ of all end-stage renal diseases [26]. In the present study, we observed that interlobar and arcuate artery resistive index values were significantly increased in type 2 diabetic patients compared with controls and also significantly increased values were observed in microalbuminuric diabetics compared with normoalbuminuric diabetics. A high renal RI may reflect increased stiffness of preglomerular arteries and increased intrarenal vascular resistance, including postglomerular circulation [27].

Hashimoto $\mathbf{J}$ and Ito S [28] reported that microalbuminuria is associated with increased RRIs and that in turn, depend on increased central pulse pressure and aortic stiffness as well as abnormal renal hemodynamics - namely increased peripheral resistance and/or increased flow pulsation. Histological studies demonstrated that RRI not only reflects changes in intrarenal perfusion and renovascular resistance but was increased in several pathological conditions, such as renal atherosclerosis and tubulointerstitial damage [29-31]. RI is a noninvasive diagnostic procedure, which strongly predicts the outcome of renal function in type 2 diabetic patients, even when GFR patterns are still normal [32].

The present study showed that interlobar and arcuate artery resistive index has strong positive correlation with ACR. Previous studies reported an association between RI and other markers of arterial stiffness as pulse wave velocity and ankle-brachial blood pressure index [33-35] and some studies reported the association between RI value and the extension of interstitial fibrosis [36] and the severity of renal impairment [37-42].

In addition present study shows that strong positive correlation of interlobar artery resistive index with HOMA-IR \& HbA1c. Chronic hyperglycemia, insulin resistance, and low-grade systemic inflammation leading to endothelial damage in diabetes [43]. Insulin resistance is characterized by pathway-selective impairment in PI3K-dependent signaling in both metabolic and vascular insulin target tissues, whereas other insulin-signaling branches, including Ras/mitogen-activated protein kinase-dependent insulin signaling typically regulates mitogenesis, growth, and differentiation [44]. In the endothelium, decreased PI3K signaling and increased mitogen-activated protein kinase signaling in response to insulin may lead to decreased production of nitric oxide (NO )and increased secretion of endothelin-1, a characteristic of endothelial dysfunction[45]. Moreover, the small and medium size vessels respond inappropriately to vasodilatory stimuli such as acetylcholine, the production of which is mediated by nitric oxide (NO) [46]. NO plays numerous physiological roles in the kidney, including control of renal and glomerular hemodynamics, by interfering at multiple and physiologically critical steps of nephron function [47]. NO is also responsible for mediation of pressure natriuresis, maintenance of medullary perfusion, blunting of tubuloglomerular reabsorption, and modulation of renal sympathetic nerve activity [48]. Youssef DM and Fawzy FM had reported a positive correlation between HbA1c and mean RI and concluded that RI is increased early in TI-DM, and it can be a predictor of DN [49]. Therefore, increased 
renal resistive index in the kidney has been regarded as an index of progressive renal damage in diabetic patients.

In conclusion, RRI might be a non invasive diagnostic marker of early renal vascular changes and is positively correlated with insulin resistance and HbA1c in type 2 diabetes mellitus. Further more studies on a larger sample size is needed to confirm our findings.

\section{References}

[1]. Fineberg D, Jandeleit-Dahm KA, Cooper ME. Diabetic nephropathy: diagnosis and treatment. Nat Rev Endocrinol 2013;9:713-723.

[2]. Forbes JM, Cooper ME.. Mechanisms of diabetic complications. Physiol Rev 2013;93:137-188.

[3]. Badal SS, Danesh FR. New insights into molecular mechanisms of diabetic kidney disease. Am J Kidney Dis 2014;63(Suppl

2):S63-S83.

[4]. Breyer MD.Drug discovery for diabetic nephropathy: trying the leap from mouse to man. Semin Nephrol 2012;32:445-45.

[5]. Gluhovschi C, Gluhovschi G, Petrica L, Timar R, Velciov S, Ionita I, Kaycsa A, Timar B.Urinary Biomarkers in the Assessment of Early Diabetic Nephropathy. J Diabetes Res. 2016; 4626125:1-13.

[6]. Caramori ML, Fioretto P, Mauer M. The need for early predictors of diabetic nephropathy risk:is albumin excretion rate sufficient? Diabetes. 2000; 49:1399-1408.

[7]. Yokoyama H, Kanno S, Takahashi S, et al. Determinants of decline in glomerular filtration rate in nonproteinuric subjects with or without diabetes and hypertension. Clin J Am Soc Nephrol.2009; 4(9):1432-1440.

[8]. Caramori ML, Fioretto P, Mauer M. Low glomerular filtration rate in normoalbuminuric type 1 diabetic patients: an indicator of more advanced glomerular lesions. Diabetes. 2003; 52(4):1036-1040.

[9]. Francesca Viazzi, Giovanna Leoncini, Lorenzo E. Derchi, Roberto Pontremoli. Ultrasound Doppler renal resistive index: a useful tool for the management of the hypertensive patient.J Hypertens. 2014 ; 32(1): 149-153.

[10]. Spatola L, Andrulli S. Doppler ultrasound in kidney diseases: a key parameter in clinical long-term follow-up.J Ultrasound. 2016 Apr 16;19(4):243-250.

[11]. Afsar B, Elsurer R. Increased renal resistive index in type 2 diabetes: Clinical relevance, mechanisms and future directions. Diabetes Metab Syndr. 2016 Aug 30. Pii; S1871-4021(16)30172-2.

[12]. Darmon M, Schnell D, Zeni F. Doppler-based renal resistive index: a comprehensive review. In: Vincent JL, editor. Yearbook of intensive care and emergency medicine. Heidelberg: Springer; 2010. pp. 331-338.

[13]. Doi Y, Iwashima Y, Yoshihara F, Kamide K, Hayashi S, Kubota Y, Nakamura S, Horio T, Kawano Y. Renal resistive index and cardiovascular and renal outcomes in essential hypertension. Hypertension. 2012;60:770-777.

[14]. Tedesco MA, Natale F, Mocerino R, Tassinario G, Calabro R. Renal resistive index and cardiovascular organ damage in a large population of hypertensive patients. J Hum Hypertens. 2007;21:291-296.

[15]. Pontremoli R, Viazzi F, Martinoli C, Ravera M, Nicolella C, Berruti V, Leoncini G, Ruello N, Zagami P, Bezante GP, Derchi LE, Deferrari G. Increased renal resistive index in patients with essential hypertension: a marker of target organ damage. Nephrol Dial Transplant. 1999; 14:360-365.

[16]. Pearce JD, Craven TE, Edwards MS, Corriere MA, Crutchley TA, Fleming SH, Hansen KJ. Associations between renal duplex parameters and adverse cardiovascular events in the elderly: a prospective cohort study. Am J Kidney Dis. 2010;55:281-290.

[17]. Matthews D.R., Hosker J.P., Rudenski A.S. Homeostasis model assessment: Insulin resistance and beta cell function from fasting plasma glucose and insulin concentrations in man. Diabetologia. 1985;13:412-419.

[18]. Parolini C, Noce A, Staffolani E, Giarrizzo GF, Costanzi S, Splendiani G. Renal resistive index and long-term outcome in chronic nephropathies. Radiology. 2009; 252: 888-896.

[19]. Remuzzi G, Schieppati A, Ruggenenti P. Clinical practice. Nephropathy in patients with type 2 diabetes. N Engl J Med. 2002;346:1145-1151.

[20]. LeRoith D, Taylor SI, Olefsky JM. Diabetes Mellitus: A Fundamental and Clinical Text. 3rd ed. Philadelphia: Lippincott William \& Wilkins; 2004. P:1,540.

[21]. Wolf G. New insights into the pathophysiology of diabetic nephropathy: from hemodynamics to molecular pathology. Eur. J. Clin. Investig. 2004;34:785-796.

[22]. Schena FP, Gesualdo L. Pathogenetic mechanisms of diabetic nephropathy. J. Am. Soc. Nephrol. 2005;16:S30-S33.

[23]. Susztak K, Bottinger EP. Diabetic nephropathy: a frontier for personalized medicine. J. Am. Soc. Nephrol. 2006;17:361-367.

[24]. Giunti S, Barit D, Cooper ME. Diabetic nephropathy: from mechanisms to rational therapies. Minerva Med. 2006;97:241-262.

[25]. Fioretto P, Mauer M. Histopathology of diabetic nephropathy. Semin. Nephrol. 2007;27:195-207.

[26]. Yashpal S. Kanwar, Lin Sun, Ping Xie, Fu-you Liu, Sheldon Chen.A Glimpse of Various Pathogenetic Mechanisms of Diabetic Nephropathy.Annu Rev Pathol. 2011; 6: 395-423.

[27]. Iwakura Y, Ito S, Morimoto R, Kudo M, Ono Y, Nezu M, Takase K, Seiji K, Ishidoya S, Arai Y, Funamizu Y, Miki T, Nakamura Y, Sasano H, Satoh F. Renal Resistive Index Predicts Postoperative Blood Pressure Outcome in Primary Aldosteronism. Hypertension. 2016 ;67(3):654-60.

[28]. Hashimoto J, Ito S. Central pulse pressure and aortic stiffness determine renal hemodynamics: pathophysiological implication for microalbuminuria in hypertension. Hypertension 2011; 58:839-846.

[29]. Sugiura T, Nakamori A, Wada A, Fukuhara Y. Evaluation of tubulointerstitial injury by Doppler ultrasonography in glomerular diseases. Clin Nephrol. 2004;61:119-126.

[30]. Boddi M, Cecioni I, Poggesi L, Fiorentino F, Olianti K, Berardino S, La Cava G, Gensini G.. Renal resistive index early detects chronic tubulointerstitial nephropathy in normo- and hypertensive patients. Am J Nephrol. 2006;26:16-21.

[31]. Ikee R, Kobayashi S, Hemmi N, Imakiire T, Kikuchi Y, Moriya H, Suzuki S, Miura S.. Correlation between the resistive index by Doppler ultrasound and kidney function and histology. Am J Kidney Dis. 2005;46:603-609.

[32]. Nosadini R, Velussi M, Brocco E, Abaterusso C, Carraro A, Piarulli F, Morgia G, Satta A, Faedda R, Abhyankar A, Luthman H, TonoloG. Increased renal arterial resistance predicts the course of renal function in type 2 diabetes with microalbuminuria.Diabetes. $2006 ; 55(1): 234-9$.

[33]. Ohta Y, Fujii K, Arima H, Matsumura K, Tsuchihashi T, Tokumoto M, Tsuruya K, Kanai H, Iwase M, Hirakata H. et al. Increased renal resistive index in atherosclerosis and diabetic nephropathy assessed by Doppler sonography. J Hypertens. 2005;23(10):19051911.

[34]. Heine GH, Gerhart MK, Ulrich C, Kohler H, Girndt M. Renal Doppler resistance indices are associated with systemic atherosclerosis in kidney transplant recipients. Kidney Int. 2005;68(2):878-885. 
[35]. Raff U, Schmidt BM, Schwab J, Schwarz TK, Achenbach S, Bar I, Schmieder RE. Renal resistive index in addition to low-grade albuminuria complements screening for target organ damage in therapy-resistant hypertension. J Hypertens. 2010;28(3):608-614.

[36]. Platt JF, Ellis JH, Rubin JM, DiPietro MA, Sedman AB. Intrarenal arterial Doppler sonography in patients with nonobstructive renal disease: correlation of resistive index with biopsy findings. Ajr. 1990;154(6):1223-1227.

[37]. Heine GH, Gerhart MK, Ulrich C, Kohler H, Girndt M. Do ultrasound renal resistance indices reflect systemic rather than renal vascular damage in chronic kidney disease? Nephrol Dial Transplant. 2006;22(1):163-170.

[38]. Galesic K, Sabljar-Matovinovic M, Tomic M, Brkljacic B. Renal vascular resistance in glomerular diseases-correlation of resistance index with biopsy findings. Coll Antropol. 2004;28(2):667-674.

[39]. Kim SH, Kim WH, Choi BI, Kim CW. Duplex Doppler US in patients with medical renal disease: resistive index vs serum creatinine level. Clin Radiol. 1992;45(2):85-87.

[40]. Petersen LJ, Petersen JR, Ladefoged SD, Mehlsen J, Jensen HA. The pulsatility index and the resistive index in renal arteries in patients with hypertension and chronic renal failure. Nephrol Dial Transplant. 1995;10(11):2060-2064.

[41]. Yura T, Yuasa S, Sumikura T, Takahashi N, Aono M, Kunimune Y, Fujioka H, Miki S, Takamitsu Y, Matsuo H. Doppler sonographic measurement of phasic renal artery blood flow velocity in patients with chronic glomerulonephritis. J Ultrasound Med. 1993;12(4):215-219.

[42]. Sari A, Dinc H, Zibandeh A, Telatar M, Gumele HR. Value of resistive index in patients with clinical diabetic nephropathy. Invest Radiol. 1999;34(11):718-721.

[43]. Tripathy D, Mohanty P, Dhindsa S, Syed T, Ghanim H, Aljada A, Dandona P.Elevation of free fatty acids induces inflammation and impairs vascular reactivity in healthy subjects.Diabetes. 2003 Dec; 52(12):2882- 2887.

[44]. Deqiu Z, Kang L, Jiali Y, Baolin L, Gaolin L. Luteolin inhibits inflammatory response and improves insulin sensitivity in the endothelium.Biochimie. 2011 Mar; 93(3):506-12.

[45]. Li R, Zhang H, Wang W, Wang X, Huang Y, Huang C, Gao F.Vascular insulin resistance in prehypertensive rats: role of PI3kinase/Akt/eNOS signaling.Eur J Pharmacol. 2010 Feb 25; 628(1-3):140-7.

[46]. Perticone F, Sciacqua A, Maio R, Perticone M, Maas R, Boger RH, Tripepi G, Sesti G, Zoccali C.Asymmetric dimethylarginine, Larginine, and endothelial dysfunction in essential hypertension.J Am Coll Cardiol. 2005; 46(3):518-2.

[47]. Mount PF, Power DA. Nitric oxide in the kidney: functions and regulation of synthesis. Acta Physiol (Oxf). 2006 Aug; 187(4):433446.

[48]. Zoccali C.The endothelium as a target in renal diseases.J Nephrol. 2007 ; 20 (12):S39-44.

[49]. Youssef DM, Fawzy FM. Value of renal resistive index as an early marker of diabetic nephropathy in children with type-1 diabetes mellitus. Saudi J Kidney Dis Transpl. 2012;23:985-92. 